\title{
The Impact of COVID-19 Pandemic on Financial Markets: Evidence from Developed and Developing Countries`Stock Markets Indexes
}

\author{
Suadiq Mehammed Hailu and Gamze Vural
}

\section{ABSTRACT}

In this study, we investigate the stock markets' reaction to the COVID-19 outbreak. For this purpose, we collected daily cumulative confirmed cases, cumulative deaths, and stock index price data from Australia, Germany, Japan, UK, USA, Brazil, China, Malaysia, South Africa, and Turkey over the period from March 11, 2020, to December 31, 2020, and examined using multiple and panel data regression. Findings reveal that the cumulative daily infection cases have a significant negative impact on the entire and first sub-period covering from March 11 to June 30, 2020. However, this negative impact of cumulative infection cases on the stock market was significant only among developed countries. In contrast, the cumulative death rate was not a fundamental factor that explains stock market price changes. The result also indicated that exchange rate has a significant negative impact on both developed and developing countries' stock markets. The overall findings of the study indicated that COVID-19 outbreak has a negative significant impact on stock markets and this impact continue until the end of the 2020 second quarter and then the impact became insignificant. Besides, the impact of the COVID-19 pandemic was different in developed and developing countries and even different from country to country.

Keywords: COVID-19, exchange rate, stock market, pandemic.
Submitted: August 8, 2021

Published : August 30, 2021

ISSN: $2507-1076$

DOI: $10.24018 /$ ejbmr.2021.6.4.1041

Suadiq Mehammed Hailu*

$\mathrm{PhD}$ Candidate in Finance, Çukurova

University, Adana, Turkey.

(e-mail: suadiq1434@gmail.com)

Gamze Vural

Assoc. Prof. Dr. Business

Administration/Finance, Çukurova

University, Adana, Turkey.

(e-mail: gvural@cu.edu.tr)

*Corresponding Author

\section{INTRODUCTION}

The performance of an economy has been affected by several natural and human-made factors. Pandemic is one of the prominent natural factors which affect the performance of the economy. According to the Dictionary of Epidemiology, a pandemic is 'an epidemic occurring worldwide or over a very wide area, crossing international boundaries, and usually affecting a large number of people [1]. In the history of human being, there are different types of pandemics occurred in different eras. For instance, Spanish influenza in 1918, the Hong Kong influenza in 1968, Asian influenza in 1957, Severe Acute Respiratory Syndrome (SARS) in 2003, HIV/AIDS, and Ebola, are among the well-known pandemic in the 20th century [2] and [3]. In addition to efforts towards understanding the health impacts of such pandemics, experts also sought to explore how pandemics affects the global economy. Myriad of Studies indicated that pandemics are significantly negatively affected the global economy [4].

A pandemic may affect the performance of an economy either by creating uncertainty about the future [5] or indirectly through containment measures. The occurrence of pandemic increases feeling of uncertainty among key economic players such as producers, consumers, and investors. As studies indicated, uncertainty is known to result in lower economic growth and tight financial situations [6] and [7]. Similarly, when a pandemic outbreak, countries took different containment measures. Travel restriction, border closing, social distancing, and stay-athome orders are among the common containment measures. Even though these measures are important for the containment of the expansion of the pandemic, they have negative side-effects on the performance of the economy.

The latest pandemic we are witnessing is COVID-2019, found in China in late 2019. On March 11, 2020, World Health Organization (WHO) affirms COVID-19 as a pandemic. This pandemic quickly transmitted into all corners of the world. According to the Our World in Data COVID-19 dataset, at the time of this paper preparation on December 31,2020, there are 83,482,639 confirmed cases and 1,818,247 deaths globally. All countries had started to take measures to control the quick dissemination of COVID19. The main measures which almost all countries applied are closing of boundary entrances, postponing international and local flights, suspending local travel, closing of supermarkets, public spaces, and educational institutions, and 'stay at home' commands [8]. Along with the abovementioned combating measures, the quick increase and expansion of COVID 19 throughout the world resulted in disrupting of local and international business [9]. The COVID-19 outbreak resulted in the short-term closedown or considerably reduction of worldwide business operations, disrupting international supply connections, productions, and business-related services, tourism, and education [10]. Supporting this, [11] stated that 'containment measures have 
had, on average, a very large impact on economic activity equivalent to a loss of about 15 percent in industrial production over a 30-day period following their implementation.

Capital markets are among the most affected sectors by COVID-19 outbreak. The impact of the COVID-19 outbreak on financial markets is highly visible on stock markets. [12] states that the main global stock markets recorded the worst performance due to the COVID-19 outbreak since 1987 stock market inception. Within six days between 23 to 28 February 2020, international stock markets recorded a $\$ 6$ trillion loss [13]. Accordingly, this paper aims to investigate the impact of COVID-19 on developed and developing countries' stock markets.

The rest of the paper continues as follows: Section 2 presents a related literature review, Section 3 outlines our sample selection procedures and methodology. Section 4 reports the results of empirical analyses. The final section concludes the study.

\section{LITERATURE REVIEW}

The stock market is one of the sectors which is highly affected by the COVID-19 outbreak. For this reason, researchers conducted different empirical studies to investigate the impact of COVID-19 on the stock market. [12] assessed the reaction of the global stock market for the COVID-19 outbreak using data from the 10 countries with top list confirmed cases. They collected the daily closing prices of indexes and daily data on the COVID-19 infections and investigated using volatility and correlation analysis. Their finding indicated that global financial market hazards have grown significantly in reaction to the pandemic.

Similarly, [14] investigated the impact of the COVID-19 pandemic on stock market returns for 64 countries covering the period from January 22 to April 17, 2020. His finding indicated that stock markets react negatively to the growth in numbers of confirmed cases and the association between the number of death and stock return was weak. Furthermore, he also indicated that stock markets strongly react to the outbreak of COVID-19 during the first two months after the initial confirmed cases. Additionally, [15] assessed the impact of the COVID-19 outbreak using 26 emerging stock markets along with exchange rate and oil price changes. They collected daily data of respective variables for the period between March 10 and April 30, 2020. They estimate the impact of COVID-19 represented by the percentage of the confirmed case from the total population using the Ordinary Least Squares (OLS) regression method. Besides to the entire period, they assessed the impact by classifying the sample period into three sub-periods to understand the changes in the impact over time. Their finding shows that the COVID-19 pandemic affects the emerging stock markets negatively and significantly until April 10. When they extend the sample period after April 17, the impact gradually declines.

Likewise, [16] examines the association between COVID19 and the stock market using data from 75 countries. He used the daily returns and return volatilities of sample indexes as the independent variable and the total number of confirmed cases per million, the total number of deaths per million as a proxy of Covid-19 data. The study period covers from January-April 2020 and employed panel regression. His finding indicated that the numbers of confirmed cases affect stock markets significantly and negatively, and the number of deaths does not have a significant impact on stock market return. Furthermore, [17] studied the impact of COVID-19 on the Chinese stock market for the period from January 10 to March 16, 2020, using panel data regression. Their finding indicated that both confirmed cases and total death caused by COVID-19 have significant negative impacts on the Chinese stock market.

In addition, [18] investigated the reaction of 21 leading stock market indices for COVID-19 outbreak using event study analysis. Their findings show that stock markets are fell quickly after the virus outbreak. Khan, Zhao, Zhang, Yang, Shah \& Jahanger [19] investigate the impact of the COVID-19 pandemic on sixteen countries' stock markets using pooled OLS regression, conventional t-test, and Mann-Whitney. The results suggest that stock markets are negatively reacted to the COVID-19 outbreak. [19] assessed the impact of COVID-19 on the stock market for selected 8 countries using conventional t-tests and nonparametric Mann-Whitney tests. They conclude that COVID-19 affects stock markets negatively for a short period of time.

In general, almost all of the above-reviewed studies confirmed that stock markets are reacted negatively to the COVID-19 pandemic, and the reaction of stock markets for COVID-19 fall after the early period of the pandemic. Most of the conducted studies covered the period maximum until the second quarter of 2020. In this regard, by expanding the time period until December 31, 2020, our study will provide the long-term picture of COVID-19 and the stock market relationship. Besides, this study will also help to understand how developed and developing countries stock market reacted to COIVD-19.

\section{DATA AND METhODOLOGY}

This paper aims to investigate the impact of COVID-19 on the stock market. For this purpose, we decided to use the stock market index as a dependent variable, and cumulative daily case and cumulative daily death as a proxy of Covid19. In addition to these, we added exchange rate in our study as a determinant of stock market price fluctuation. After deciding the dependent and independent variables, we proceed to select sample countries. Depending on the economic development and geographic location, we selected five countries from developed economies and five from developing economies. Following this, we selected the main stock index from each country. Sample countries, their main index, and used exchange rates are summarized in the Table I.

Once identifying the dependent variable (stock index) and independent variables (cumulative daily case, cumulative daily death, and exchange rate), we specified the period which our study covered. We used March 11, 2020, as a starting date, which is a date that the World Health Organization (WHO) declared COVID-19 as a pandemic. Accordingly, our study covered the period from March 11, 2020, to December 31, 2020. The daily cumulative COVID19 case and death of each country are downloaded from 
https://ourworldindata.org, and daily stock index price and exchange rates are collected from https://www.investing.com.

TABLE I: SELECTED COUNTRIES, INDEXES, AND EXCHANGE RATES

\begin{tabular}{cccc}
\hline Status & Country & Index & Exchange Rate \\
\hline \multirow{5}{*}{ Developed } & Australia & ASX 200 & USD/AUD \\
& Germany & DAX 30 & USD/EUR \\
& Japan & Nikkei 225 & USD/JPY \\
& UK & FTSE 100 & USD/GBP \\
& USA & S\&P 500 & EUR/USD \\
\hline \multirow{5}{*}{ Developing } & Brazil & BOVESPA & USD/BRL \\
& China & SZCI & USD/CNY \\
& Malaysia & KLCI & USD/MYR \\
& South Africa & SE Top 40 & USD/ZAR \\
& Turkey & BIST 100 & USD/TRY \\
\hline
\end{tabular}

We applied a filter to improve the raw data. COVID-19 data are available for each day; however, stock prices and exchange rates were not available for weekends or national holidays. Accordingly, we dropped COVID-19 observations on the weekends and national holidays. To transfer all variables into the same format, we use daily changes of all variables. We calculate the daily change of our variables as follows:

\begin{tabular}{ccc}
\multicolumn{3}{c}{ TABLE II: LISTS OF VARIABLES AND THEIR DAILY } \\
CHANGE CALCULATION FORMULA \\
\hline Variables & Symbols & Formula \\
\hline $\begin{array}{c}\text { Stock Index Return } \\
\text { Cumulative Daily } \\
\text { Case Rate }\end{array}$ & Index_R & Index_R $=\left(\frac{P_{t-1} P_{t-1}}{P_{t-1}}\right)$ \\
$\begin{array}{c}\text { Cumulative Daily } \\
\text { Death Rate }\end{array}$ & CDCR & CDCR $=\left(\frac{C D C_{t-} C D C_{t-1}}{C D C_{t-1}}\right)$ \\
Exchange Rate & ER & CDDR $=\left(\frac{C D D_{t-} C D D_{t-1}}{C D D_{t-1}}\right)$ \\
\hline
\end{tabular}

To check whether COVID-19 has an effect on the stock market, we employed multiple regression and panel regression. Firstly, we employed multiple regression for each country separately to assess the impact of COVID-19 on each sample country. Multiple regression analysis is used to determine the association between two or more variables that have a cause and effect relationship and to make estimations about the issue depending on the relation [20]. Thus, our regression model described statistically as follows:

Inde_ $R_{t}=\beta_{0}+\beta_{1 t} C D C R_{1 t}+\beta_{2 t} C D D R_{2 t}+\beta_{3 t} E R_{3 t}+\varepsilon_{t}$

where $I n d e_{-} R_{t}$ is the dependent variable at time $t$ (in our case it is Stock index return), CDCR, CDDR and ER are the explanatory variables. $\varepsilon_{t}$ the stochastic disturbance term, $\beta$ is the intercept term. The coefficient $\beta_{1}, \beta_{2}$ and $\beta_{3}$ are called the regression coefficients.

Secondly, in order to check the general impact of COVID-19 on the stock market and its specific impact on developed and developing countries' stock markets, we employed the panel data regression method by transforming our data into longitudinal data. Instead of using only crosssection or time-series data, panel data can take into account heterogeneity among units, suitable to analyze the dynamics of change, and better to find out and evaluate effects [21].
Finally, following the findings that indicate the early impact of COVID-19 on the global economy as more significant than the subsequent periods [22], we categorized our study period into three sub-periods to trace the impact of COVID-19 on each period. For this purpose, 'Period I' covers from March 11 to June 30,2020, 'Period II' covers from July 1 to September 30, while 'Period III' covers from October 1 to December 31, 2020. We hypothesized that the impact of COVID-19 on the stock market will be significant in the first period and decrease in the next periods.

\section{RESUlTS AND DisCUSSION}

We started the empirical analysis by investigating the impact of COVID-19 on selected 10 sample countries. First, we present the association between dependent and independent variables using Pearson's correlation coefficient. We calculated the correlation between each country's stock index return with respect to each country's cumulative daily COVID-19 case rate, cumulative daily death rate, and exchange rate. Pearson's correlation coefficients are presented in Table III below.

Table III indicated that from the sample countries' stock indexes, ASX200, FTSE100, S\&P 500, and BIST 100 are significantly negatively correlated with their respected CDCR. On the other hand, FTSE100, S\&P500, BVSP, and KLCI are significantly negatively correlated with their respected CDDR. In addition to this, the result revealed a significant negative correlation between exchange rate and stock indexes such as ASX200, FTSE100, BVSP, and KLCI. From our sample countries, the UK stock index was significantly negatively correlated with CDCR, CDDR, and ER.

After analyzing the association between our dependent and independent variables, we investigated the impact of COVID-19 on sample countries' stock markets using multiple regression and presented the regression coefficients in Table IV below.

Table IV displays the effects of COVID-19 on the stock market in the three sub-periods and the full sample period. Employing the regression for each sub-period is important to see the periodical impacts of COVID on the stock market. In the first sub-period which covers from March 11 to June 30, 2020, CDCR has a significant negative effect on ASX200, DAX, and S\&P500. However, in the second and third sub-periods, the impact of CDCR on the stock market was not statistically significant. On contrary, CDDR does not have a significant impact on sample indexes except on BVSP in the first, and Nikkei225 in the second sub-periods.

When we see the impact of COVID-19 during the full sample period, the result shows a significant negative effect of CDCR on ASX200, DAX, and S\&P500. The data further revealed that CDDR has a negative significant effect on Nikkei225 and BVSP. 
TABLE III: THE PEARSON CORRELATION COEFFICIENTS

\begin{tabular}{ccccccccccc}
\hline & ASX200 & DAX & Nikkei225 & FTSE100 & S\&P500 & BVSP & SZCI & KLCI & SET0P40 & BIST100 \\
\hline CDCR & $-.21^{*}$ & -.097 & .003 & $-.167 *$ & $-.226^{* *}$ & .145 & .07 & -.099 & -.0 .09 & $-.159^{*}$ \\
CDDR & .27 & .003 & -.119 & $-.152^{*}$ & $-.143^{*}$ & $-.150^{*}$ & .01 & $-.143^{*}$ & .116 & -.076 \\
ER & $-.16^{*}$ & -.034 & -.063 & $-.164 *$ & -0.092 & $-.147^{*}$ & .11 & $-.259^{*}$ & -.124 & -.126 \\
\hline
\end{tabular}

$* *$. Correlation is significant at the $1 \%$ level.

$*$. Correlation is significant at the $5 \%$ level.

TABLE IV: MULTIPLE REGRESSION RESULTS

\begin{tabular}{|c|c|c|c|c|c|c|c|c|c|c|c|c|}
\hline & \multicolumn{3}{|c|}{ Period I } & \multicolumn{3}{|c|}{ Period II } & \multicolumn{3}{|c|}{ Period III } & \multicolumn{3}{|c|}{ All Sample } \\
\hline & CDCR & CDDR & ER & CDCR & CDDR & ER & CDCR & CDDR & ER & CDCR & CDDR & ER \\
\hline ASX200 & $-.05 * *$ & .09 & -.47 & .05 & .01 & .09 & 1.51 & .23 & -.01 & $-.05 * *$ & .08 & $-.33 *$ \\
\hline DAX & $-.28 * *$ & .16 & -.53 & -.12 & 3.70 & .20 & -.02 & -.09 & -.07 & $-.23 * *$ & .13 & -.23 \\
\hline Nikkei225 & .06 & -.09 & -.56 & .10 & .11 & .21 & .48 & $-.39 *$ & .12 & .06 & $-.08 *$ & -.28 \\
\hline FTSE100 & -.02 & .004 & -.64 & .04 & -.02 & -.06 & .02 & .41 & .19 & -.02 & .004 & $-.38 *$ \\
\hline S\&P500 & $-.13 * *$ & .11 & -.80 & .11 & .29 & -.60 & 0.13 & -0.28 & 0.16 & $-.13 * *$ & .10 & -.55 \\
\hline BVSP & .05 & $-.04 *$ & -.08 & -.74 & 1.53 & $-.4 * *$ & -.05 & .57 & $-.63 * *$ & .05 & $-.04 * *$ & -.13 \\
\hline SZCI & -3.66 & .04 & -.03 & 2.1 & -2.4 & $2 *$ & 3.2 & -.23 & .24 & 1.08 & -.01 & .58 \\
\hline KLCI & 0.03 & -0.01 & $-1 * *$ & 0.07 & -0.26 & 0.18 & -0.07 & 0.10 & $-1 *$ & 0.02 & -0.01 & $-.96^{* *}$ \\
\hline SET0P40 & -.02 & .01 & -.18 & .05 & .03 & -.20 & -.28 & .14 & -.14 & -.005 & .011 & -.184 \\
\hline BIST100 & -.004 & .000 & $-1 * *$ & -0.24 & 0.14 & 0.61 & -0.41 & 0.05 & 0.02 & -0.01 & 0.00 & -0.20 \\
\hline
\end{tabular}

$* *$ and $*$ indicate significance at $1 \%$ and $5 \%$, respectively.

In general, the regression result in Table IV indicated that the impact of COVID-19 on the stock market was significant during the first sub-period and the impact was decreased in the consequent sub-periods. This result was in line with [19] finding. Their study indicated that COVID-19 affects stock markets negatively for a short period of time. However, the finding regarding the impact of COVID-19 on individual stock markets does not confirm the study conducted by [23] and [17]. The finding of [23] indicated that COVID-19 daily infection case in Australia has a significant positive effect on the ASX 200 performance. Nevertheless, in contrary to their findings, our study shows that daily infection case in Australia has a significant negative impact on ASX 200 performance. Similarly, [17] show that both confirmed cases and total death caused by COVID-19 have significant negative impacts on the Chinese stock market. Contrary to [17], our study indicated that COVID-19 does not have significant impact on the stock market. These conflicting results may be attributed to the time period difference covered in our study and the above mentioned two studies.

Once assessing the impact of COVID-19 pandemic on individual sample countries, in this section we examined its impact on all samples as a single entity using panel regression. There are three common panel data regression techniques namely pooled Ordinary Least Square (OLS) model, fixed-effects model, and random effects model [24]. Among these types of panel regression models, pooled OLS model is not considered appropriate for this study since it did not take into account the effect of time and individual dimensions. We used the Hausman test to decide whether a fixed or random effect model is appropriate for our data. According to the Hausman test, random effect model is selected if the p-value is more than $5 \%$ while fixed-effect model is considered appropriate if the p-value is less than $5 \%$ [25].

Consequently, we employed the Hausman test for all models and their p-value is more than $5 \%$, indicating the appropriateness of random effect model to our data. Accordingly, we employed the Radom effect model for all samples, and the result is presented in the following tables.
TABLE V: RANDOM EFFECT PANEL DATA REgRESSION FOR ALL SAMPLES

\begin{tabular}{ccc}
\hline Period & Variable & Coefficient \\
\hline \multirow{2}{*}{ Period I } & CDCR & -0.005 \\
& CDDR & -0.003 \\
& ER & $-0.179^{* *}$ \\
Period II & CDCR & 0.073 \\
& CDDR & -0.011 \\
& ER & $-0.152^{*}$ \\
Period III & CDCR & -0.030 \\
& CDDR & 0.026 \\
& ER & -0.130 \\
All Sample & CDCR & -0.005 \\
& CDDR & -0.002 \\
& ER & $-0.172 * *$ \\
\hline
\end{tabular}

**. statistical significance $1 \%$ level.

*. statistical significance at the $5 \%$ level.

Table V indicated that CDCR and CDDR did not have a significant impact on stock market return in the full sample period and in all sub-periods. However, the exchange rate has a negative significant impact in all periods. We believe that the observed non-significant effect of CDCR on stock market could be related to the fact that our model examined its effect together with other variables such as exchange rate. Hence, to examine the unique effect of CDCR on stock market we run hierarchical regression analysis. In the first model, we include CDCR only, then in the second model we add CDDR in the model, and finally, in the third model ER was added. These models help us to examine the unique effect of CDCR on stock market.

TABLE VI: HIERARCHICAL REGRESSION RESULTS OF FOR ALL SAMPLE

\begin{tabular}{|c|c|c|c|c|}
\hline \multirow{2}{*}{\multicolumn{2}{|c|}{ Variables }} & \multicolumn{3}{|c|}{ Stock Market Index Returns } \\
\hline & & Model 1 & Model 2 & Model 3 \\
\hline \multirow{4}{*}{ Period I } & CDCR & $-.083^{*}$ & -.060 & -.056 \\
\hline & CDDR & & -.045 & -.043 \\
\hline & ER & & & $-.112 * *$ \\
\hline & R-squared & .007 & .008 & .021 \\
\hline \multirow{4}{*}{ Period II } & CDCR & .095 & .103 & .104 \\
\hline & CDDR & & -.013 & -.016 \\
\hline & ER & & & $-.078 *$ \\
\hline & R-squared & .009 & .009 & .015 \\
\hline \multirow{4}{*}{ Period III } & CDCR & -.031 & -.048 & -.046 \\
\hline & CDDR & & .027 & .027 \\
\hline & ER & & & -.073 \\
\hline & R-squared & 001 & 001 & 007 \\
\hline \multirow{4}{*}{ All Sample } & CDCR & $-.064 * *$ & -.045 & -.041 \\
\hline & CDDR & & -.037 & -.035 \\
\hline & ER & & & $-.104 * *$ \\
\hline & $\mathrm{R}$-squared & .004 & .005 & .016 \\
\hline
\end{tabular}

*. statistical significance at the $5 \%$ level. 
As indicated in Table VI, when we used hierarchical regression for all pooled panel data, CDCR became a significant factor that affects the stock market negatively in the first sub-period and in the full sample. However, the cumulative daily death rate is not a significant factor both in panel data regression and hierarchical regression.

Overall, the finding in this section indicated that cumulative daily infection cases have a significant impact on the full sample period and on the first sub-period which covers from March 11 to June 30, 2020. However, after the end of the first sub-period, the effect of COVID-19 on the stock market was not significant. In addition, the daily cumulative death result from COVID-19 was not a significant factor that explains stock market return fluctuations. The result of this study confirms the findings of [14], [12], and [16]. Thus, [14] indicated that stock markets strongly react to the outbreak of COVID-19 during the first two months after the initial confirmed cases. Regarding daily cumulative death rates, similar to our finding, [16] concluded that the number of deaths does not have a significant impact on stock return.

To examine whether the COVID-19 outbreak affects stock markets differs as a function of the countries' economic status, we applied random effect panel data regression for developed and developing countries separately. The result of separate panel data regression for developed and developing countries are presented in Table VII. As a proxy of developed stock markets, we use the data of Australia, German, Japan, the UK, and the USA. In the representation of developing countries' stock markets, we use data from Brazil, China, Malaysia, South Africa, and Turkey.

As depicted in Table VII, among developed countries, CDCR and ER significantly negatively affected the stock market in the full study period and also in the first subperiod. On contrary, CDDR does not has a significant impact on all periods and all sub-periods. In the case of developing countries, however, both cumulative daily cases and death changes did not show any significant impact on the developing countries' stock market. In contrast, exchange rate changes have a negative significant impact on developing countries' stock markets.

TABLE VII: RANDOM EFFECT PANEL DATA REGRESSION FOR DEVELOPED COUNTRIES

\begin{tabular}{|c|c|c|c|c|c|}
\hline Status & Variable & Period I & Period II & Period III & All \\
\hline \multirow{3}{*}{$\begin{array}{l}\text { D } \\
\frac{0}{0} \\
\frac{0}{0} \\
0 \\
0\end{array}$} & CDCR & $-0.039 * *$ & 0.078 & 0.020 & $-0.034 * *$ \\
\hline & CDDR & 0.004 & -0.004 & 0.027 & 0.005 \\
\hline & ER & $-0.497 * *$ & 0.007 & 0.095 & $-0.315^{* *}$ \\
\hline \multirow{3}{*}{$\begin{array}{l}\stackrel{0}{\Xi} \\
\frac{0}{0} \\
\frac{0}{0} \\
\stackrel{0}{0}\end{array}$} & CDCR & 0.001 & 0.079 & -0.085 & 0.002 \\
\hline & CDDR & -0.004 & -0.026 & 0.054 & -0.004 \\
\hline & ER & $-0.133^{*}$ & $-0.200 *$ & $-0.199 *$ & $-0.146^{* *}$ \\
\hline
\end{tabular}

**. statistical significance at the $1 \%$ level.

*. statistical significance at the $5 \%$ level.

In sum, the empirical results of this section indicated that the COVID-19 outbreak has a different impact on developed and developing countries' stock markets. During the full sample period which covers from March 11 to
December31,2020, and the first sub-period that covers from 30, 2020om March 11 to June 30,2020, cumulative daily infection cases have a significant negative impact on developed countries' stock markets, while its effect is not significant on developing countries' stock markets. Cumulative daily death was not a significant impact in both developed and developing countries' stock markets. As indicated above, this finding is in consensus with the finding of [16]. His finding indicated that the daily death rate does not have a significant impact on stock return.

\section{CONCLUSION}

This study aims to examine the impact of the COVID-19 outbreak on developed and developing countries' stock markets. For this purpose, we collected the daily price of stock indexes, daily cumulative infection cases, daily cumulative deaths, and daily exchange rates for each sample countries covering the period from March 11, which WHO declared COVID-19 as a pandemic, to December 31, 2020. We divide the sample period into three sub-periods; Period I (March 11 to June 30,200), Period II (July 1 to September 30), and Period III (October 1 to December 31, 2020), and investigated using multiple regression and panel data regression.

Initially, using regression analysis we assessed the impact of COVID-19 pandemic variables and exchange rate on individual sample countries' stock index. The result indicated that ASX200, DAX, and S\&P500 are significantly negatively affected by daily cumulative infection cases. Then, using hierarchical regression we investigated the impact of COVID-19 pandemic variables and exchange rate on overall stock indexes. The finding indicated that cumulative daily infection case has a significant impact on the full sample period and on the first sub-period. Finally, using panel data regression we examined the impact of the COVID-19 pandemic on developed and developing countries' stock markets by classifying the sample countries based on their economic status. The outcome of the study shows that CDCR and ER are significantly negatively affected developed countries' stock market in the full study period and also in the first sub-period. Contrary to this, however, the impact of CDCR on developing countries' stock market was not significant. The result also indicated that the exchange rate affects developing countries' stock market negatively significantly. Nevertheless, the daily cumulative death does not have a significant impact on both developing and developed countries' stock markets.

The overall finding of this study indicated that the COVID-19 outbreak has a negative significant impact on stock markets and this impact continue until the end of the 2020 second quarter and then gradually disappeared. Besides, the result also indicated that the impact of the COVID-19 pandemic was different in developed and developing countries and even different from country to country. 


\section{REFERENCES}

[1] Porta, M. (Ed.). (2008). A dictionary of epidemiology. Oxford university press.

[2] Kilbourne, E. D. (2006). Influenza pandemics of the 20th century. Emerging infectious diseases, 12(1), 9.

[3] Jonung, L., \& Roeger, W. (2006). The macroeconomic effects of a pandemic in Europe-A model-based assessment. Available at SSRN 920851.

[4] Qiu, W., Rutherford, S., Mao, A., \& Chu, C. (2017). The pandemic and its impacts. Health, culture and society, 9, 1-11.

[5] Song, L., \& Zhou, Y. (2020). The COVID-19 Pandemic and Its Impact on the Global Economy: What Does It Take to Turn Crisis into Opportunity? China \& World Economy, 28(4), 1-25.

[6] Ahir, H., Bloom, N., \& Furceri, D. (2020). Global uncertainty related to Coronavirus at Record High. IMF Blog, april.

[7] Mishra, P. K., \& Mishra, S. K. (2020). Corona Pandemic and Stock Market Behaviour: Empirical Insights from Selected Asian Countries. Millennial Asia, 0976399620952354.

[8] Evans, O. (2020). Socio-economic impacts of novel coronavirus: The policy solutions. BizEcons Quarterly, 7, 3-12.

[9] Sharma, P., Leung, T. Y., Kingshott, R. P., Davcik, N. S., \& Cardinali, S. (2020). Managing uncertainty during a global pandemic: An international business perspective. Journal of Business Research, 116, 188-192.

[10] Barua, S. (2020). Understanding Coronanomics: The economic implications of the coronavirus (COVID-19) pandemic. Available at SSRN 3566477.

[11] Deb, P., Furceri, D., Ostry, J. D., \& Tawk, N. (2020). The economic effects of Covid-19 containment measures.

[12] Ozili, P. K., \& Arun, T. (2020). Spillover of COVID-19: impact on the Global Economy. Available at SSRN 3562570.

[13] Zhang, D., Hu, M., \& Ji, Q. (2020). Financial markets under the global pandemic of COVID-19. Finance Research Letters, 101528

[14] Ashraf, B. N. (2020). Stock markets' reaction to COVID-19: cases or fatalities? Research in International Business and Finance, 101249.

[15] Topcu, M., \& Gulal, O. S. (2020). The impact of COVID-19 on emerging stock markets. Finance Research Letters, 36, 101691.

[16] Erdem, O. (2020). Freedom and stock market performance during Covid-19 outbreak. Finance Research Letters.

[17] Al-Awadhi, Abdullah M.; Alsaifi, Khaled; Al-Awadhi, Ahmad; Alhammadi, Salah (2020). Death and contagious infectious diseases: Impact of the COVID-19 virus on stock market returns. Journal of Behavioral and Experimental Finance, 27(), 100326-. doi: 10.1016/j.jbef.2020.100326

[18] Liu, H., Manzoor, A., Wang, C., Zhang, L., \& Manzoor, Z. (2020). The COVID-19 outbreak and affected countries stock markets response. International Journal of Environmental Research and Public Health, 17(8), 2800.

[19] Khan, K., ZHAO, H., Zhang, H., Yang, H., Shah, M. H., \& Jahanger, A. (2020). The impact of COVID-19 pandemic on stock markets: An empirical analysis of world major stock indices. The Journal of Asian Finance, Economics, and Business, 7(7), 463-474.

[20] Qing He, Junyi Liu, Sizhu Wang \& Jishuang Yu (2020) The impact of COVID-19 on stock markets, Economic and Political Studies, 8:3, 275-288, DOI:10.1080/20954816.2020.1757570

[21] Uyanık, G. K., \& Güler, N. (2013). A study on multiple linear regression analysis. Procedia-Social and Behavioral Sciences, 106, 234-240.

[22] Gujarati, D. (2004). Basic Econometrics. 4th ed. New York: McGraw Hill,

[23] Weiss, M., Schwarzenberg, A., Nelson, R., Sutter, K. M., \& Sutherland, M. D. (2020). Global economic effects of COVID-19. Congressional Research Service.

[24] Brueckner, M., \& Vespignani, J. (2020). Covid-19 infections and the performance of the stock market: An empirical analysis for Australia.

[25] Yaffee, R. (2003). A primer for panel data analysis. Connect: Information Technology at NYU, 1-11.

[26] Zulfikar, R., \& STp, M. M. (2019). Estimation model and selection method of panel data regression: an overview of common effect, fixed effect, and random effect model.

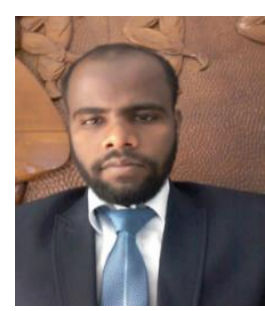

Suadiq Mehammed Hailu is a PhD Candidate in Finance at Cukurova University, Adana, Turkey. $\mathrm{He}$ has an MA in Banking and Finance from Ankara Yildrim Beyazit University, B.Sc. in Islamic Economics, Banking and Finance from International Open University and BA in Banking and Finance from Jimma University. His research focuses on both conventional and Islamic finance areas; and published a couple of research on both disciplines.

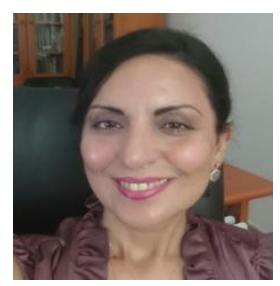

Dr. Gamze Vural is an associate professor of finance at Çukurova University, Faculty of Economics and Administrative Sciences. Vural has a Ph.D. in Finance from Çukurova University, Institute of Social Sciences. She has nearly fifteen years of experience in teaching and research. Gamze Vural has published studies on various fields of finance. 